3 Thomford, N. R., Woolner, L. B., and Clagett, O. T., fournal of Thoracic and Cardiovascular Surgery, 1965, 49, 357.

Effler, D. B., and Blades, B., Fournal of Thoracic and Cardiovascular Surgery, 1948, 17, 27.

${ }^{5}$ Hood, R. T., jun., McBurney, R. P., and Clagett, O. T., fournal of Thoracic and Cardiovascular Surgery, 1955, 30, 81.

6 Ehrenhaft, J. L., Lawrence, M. S., and Sensenig, D. M., Archives of Surgery, 1958,77,606.

7 Parker, R. G., Fournal of Thoracic and Cardiovascular Surgery, 1958, 36, 81 .

${ }^{8}$ Rowlandson, R., British fournal of Diseases of the Chest, 1958, 52, 190.

${ }_{9}^{8}$ Rowlandson, R., British Fournal of Diseases of the Chest, 1958,

${ }_{10}^{9}$ Patten, J. F., and Mallis, N. J., Fournal of Urology, 1959, 81, 457. 42, 540 .

1 Friedman, M., and Purkayashtha, M. C., fournal of Urology, 1960, 84, 360

12 Sellors, T. H., British Medical fournal, 1970, 2, 253.

${ }^{3}$ Smithers, D. W., in $A$ Clinical Prospect of the Cancer Problem, ed. D. W. Smithers, p. 26. Edinburgh, Livingstone, 1960.
14 Smithers, D. W., Lancet, 1969, 2, 949.

Asvall, J., Sanderud, A., and Nitter, L., Acta Radiologica. Therapy, Physics, Biology, 1967, 6, 351

${ }^{16}$ Breur, K., European fournal of Cancer, 1966, 2, 157

${ }_{17}$ Moersch, R. N., and Clagett, O. T., Surgery, 1961, 50, 579

Clagett, O. T., and Woolner, L. B., Medical Clinics of North America, $1964,48,939$.

"Polk, J. W., Bailey, A. H., and Kalagayan, H., American fournal of Surgery, 1965, 110,737.

20 Spratt, J. S., and Yuen, P. F., Cancer Bulletin, (Washington), 18, 110

1 Alexander, J., and Haight, C., Surgery, Gynecology and Obstetrics, 1947, $85,129$.

2 Wilkins, $\mathrm{E}, \mathrm{W}$, jun Burke, J. F and Head, J. M., fournal of Thoracic and Cardiovascular Surgery, 1961, 42, 298.

and Cardiovascular Surgery, $1961,42,298$.

3 Gliedman, M. S., Horowitz, S., and Lewis, F. J., Surgery, 1957, 42, 521 Jensik, R. J., and Van Hazel, W., Surgery, 1958, 43, 1002

25 Wheatley, A., and Howard, N., British Fournal of Surgery, 1967, 54, 364 ${ }^{26}$ Blandy, I. P., Hospital Medicine, 1966, 1, 133.

\title{
Standardization of the One-stage Prothrombin Time Test for the Control of Anticoagulant Therapy: Availability and Use of Thromboplastin Reference Preparations
}

\author{
ROSEMARY BIGGS, D. R. BANGHAM
}

British Medical fournal, 1971, 3, 470-471

\section{Introduction}

Prothrombin time determinations are used for the control of anticoagulant therapy with coumarin drugs. The results obtained at different centres at present give different assessments of the abnormality because the thromboplastin preparations do not have the same sensitivity to the coumarin defect. There now seems to be general agreement that the thromboplastin sensitivity ratio method of Biggs and Denson ${ }^{1}$ using characterized thromboplastin preparations can be used to correlate the prothrombin time results obtained at different laboratories. Another approach to the standardization problem has proposed the use of standard reference plasma samples. ${ }^{2}$ This is still under investigation, since possibly characterized thromboplastin preparations will be used together with reference plasma preparations to give a complementary system. At present the plasma standards have not been studied with a wide range of thromboplastin preparations at the Laboratory of Biological Standards. It is, however, already possible to use the characterized thromboplastin preparations with individual fresh normal and abnormal samples from patients stabilized on anticoagulant therapy. This communication concerns the availability and use of the thromboplastin reference preparations.

\section{Preparations}

At present five preparations of thromboplastin are available from the Division of Biological Standards. Two (2 and 3 below) have been characterized and can now be issued for standardization procedures. The other three are under study and will be available shortly for general use.

\footnotetext{
Oxford Haemophilia Centre, Research Laboratory, Churchill Hospital, Oxford OX3 7LJ

ROSEMARY BIGGS, M.D., Director

Division of Biological Standards, National Institute for Medical Research, London N.W.7

D. R. BANGHAM, M.B., B.s., Director
}

Thromboplastin $1(69 / 223)$ : human brain, plain, to be reconstituted with $1 \mathrm{ml}$ distilled water.

Thromboplastin $2(67 / 40)$ : human brain with fibrinogen and factor $\mathrm{V}$, to be reconstituted with $2.2 \mathrm{ml} 3.2 \mathrm{mmol} \mathrm{CaCl}$.

Thromboplastin $3(68 / 434)$ : bovine brain with fibrinogen and factor $\mathrm{V}$, to be reconstituted with $2 \cdot 2 \mathrm{ml} 3 \cdot 2 \mathrm{mmol} \mathrm{CaCl}$.

Thromboplastin $4(70 / 115)$ : rabbit brain with fibrinogen and factor $\mathrm{V}$, to be reconstituted with $2.2 \mathrm{ml}$ distilled water.

Thromboplastin $5(70 / 178)$ : rabbit brain, plain, to be reconstituted with $1 \mathrm{ml}$ distilled water.

This range of thromboplastin reference preparations has been provided to take into consideration the various modifications of the one-stage prothrombin time in use in different parts of the world. All these types of thromboplastin preparations have been sealed in ampoules under conditions which should ensure their long-term stability as reference materials.

A collaborative study carried out in Leiden, Oslo, and Oxford in $1969^{3}$ showed that the three laboratories agreed closely when they tested preparations $2(67 / 40)$ and $3(68 / 434)$ on coded common abnormal plasmas. In all laboratories the same clotting time ratio was obtained for each of these coded plasmas. The same relative sensitivity ratio for both thromboplastins was obtained in all laboratories, both with common abnormal plasmas and with the local abnormal plasma used in the three laboratories. This shows that thromboplastin preparation 2 $(67 / 40)$ can be used as a reference preparation to calibrate bovine thromboplastin preparations with respect to the coumarin defect. Additional work suggests that the human brain preparation $1(69 / 223)$ can also be similarly calibrated. A collaborative study is in progress to confirm the results for the human brain preparation $1(69 / 223)$ and to calibrate the rabbit brain preparations (4 and 5) (70/115 and 70/178) in terms of preparation 2 (67/40).

Meanwhile we feel that ampoules of the two types of thromboplastin preparations already studied (2 and 3) (67/40 and $68 / 434$ ) should be made available for use. A sensitivity ratio of 2.0 can be assigned by definition to preparation $2(67 / 40)$. The collaborative study showed that thromboplastin bovine preparation $3(68 / 434)$ was determined as having a ratio of about 2.0 in terms of $67 / 40$. Other thromboplastin preparations can be calibrated in terms of preparation $2(67 / 40)$. Memoranda of information about each reference preparation will be issued with ampoules, together with instructions on how to calibrate and apply the sensitivity ratio prepared by Denson. ${ }^{4}$ 
In view of the great deal of collaborative work which has been invested in them, these preparations should be kept primarily for the purpose of calibration of other national reference preparations, especially if countries agree to organize control of thromboplastin preparations. It is intended that they should not be used as a working reference preparation for routine work. Whether or not official control exists, it is hoped that manufacturers will voluntarily agree to calibrate their production batches in terms of an appropriate thromboplastin reference preparation.

In Great Britain a liquid phenolized preparation of human brain - the British Comparative Thromboplastin, made by Dr. L. Poller (Department of Haematology, Withington
Hospital, Manchester)-provides a national reference material. The relative activities of this material and of thromboplastin 1 (69/223), with which it is comparable, will ultimately be determined.

\section{References}

${ }^{1}$ Biggs, R., and Denson, K. W. E., British Medical fournal, 1967, 1, 84. Miale, J. B., and LaFond, D. J., American fournal of Clinical Pathology, $1967,47,40$.

${ }^{3}$ Bangham, D. R., Biggs, R., Brozovic, M., and Denson, K. W. E., Thrombosis et Diathesis Haemorrhagica, 1970, Suppl. No. 40, p. 341.

4 Denson, K. W. E., Fournal of Clinical Pathology, 1971, 24, 460.

\section{Any Questions?}

We publish below a selection of questions and answers of general interest

\section{Tuberculosis in Wild Deer}

Do wild deer suffer from tuberculosis? Would it be possible for deer to infect cows when they graze alongside each other?

Wild deer of various species appear to be susceptible to tuberculosis. ${ }^{1}$ Infection of cows would be possible given suitable conditions of contact as might be achieved during grazing the same pasture.

' Discases in Free-living Wild Animals, cd. A. McDiarmid, London, Acad:mic Press, 1969.

\section{B.P. at Insurance Examinations}

$A$ patient aged 45 and about a stone $(6.4 \mathrm{~kg})$ overweight was found to have a blood pressure of 140100 at a routine insurance examination. Is this sufficient evidence to suggest a diagnosis of hypertension, and, if so, what treatment is advisable?

Life insurance company statistics from the United States suggest that a patient aged 45 with a blood pressure of $140 / 100$ has more than twice the chance of dying before he is aged 65 compared with the average man of his age. The applicability of the American life companies' experience, which was mainly gathered with insurance policies issued in the 1930's and 1940's, to the British population in the 1970's has been doubted. Life insurance examinations probably tend to underestimate the pressure because most doctors take several readings and record the lowest. It is also likely that a higher proportion of hypertensives in earlier years were secondary to chronic glomerulonephritis and had a much worse prognosis than a man with mild, essential hypertension today. Even so, there is little doubt that the patient described in this question has a substantially worse prognosis than average. The question whether or not he has hypertension is almost irrelevant. It depends upon what level of blood pressure and under what circumstances an empirical definition of hypertension is based. What matters to the patient and his physician is the risk carried by a particular level of pressure.

There is no satisfactory evidence to indicate whether any form of treatment would benefit him. The Veterans Administration ${ }^{1}$ second trial included patients with pressures at this level but the benefits of treatment were much less obvious in them than in those with slightly higher levels. A reasonable clinical policy for handling this patient would be as follows: to see him on three or four occasions over a period and persuade him to lose weight. If he smokes it would be necessary to persuade him to stop but it is best not to do this simultaneously with weight reduction, otherwise both measures may fail. If his blood pressure remains at a level of about 140/100 after weight reduction and cessation of smoking, there would be strong grounds for advising mild anti-hypertensive treatment with a thiazide diuretic. Although this policy seems reasonable in the light of our existing knowledge there is no completely convincing evidence that it is better than doing nothing at all apart from stopping the patient smoking.

\section{Veterans Administration Co-operative Study Group on Antihypertensive Agents, Fournal of the American Medical Association, 1970, 213, 1143.}

\section{Toxicity of Oranges' Dye}

What is the dye that oranges are sprayed with to "improve" their colour, and is it a health hazard to orange or marmalade eaters?

Probably the dye referred to is Citrus Red No. 2 (1-(2,5dimethoxyphenylazo)-2-naphthol). All available toxicological data on this dye were examined by the Joint F.A.O. W.H.O. Expert Committee on Food Additives in 1969. ${ }^{1}$ This committee considered that certain discrepancies in the findings of various workers and the differences between oral and parenteral effects needed explanation and recommended that until further data are available the dye should not be used in food. The U.S.A. authorities, however, still permit the use of small amounts to colour the skins of oranges but only those that are not intended for processing into beverages or food. ${ }^{2}$ In the U.K. it is illegal to import or sell oranges that have been coloured with Citrus Red No. 2. Under the Colouring Matter in Food Regulations $(1966)^{3}$ orange skins may be coloured only by dyes which appear in a permitted list and then only if "Colour Added" is printed clearly on the fruit. Dyes on this permitted list are considered by committees of experts at the Ministry of Agriculture, Food, and Fisheries and Department of Health and Social Security to be without hazard to health when used in food in technologically suitable amounts. While the safety of Citrus Red No. 2 is thus at the present time in some doubt, any colorant which might occur on oranges or in marmalade in the U.K. will be without hazard to health.

1 Joint F.A.O./W.H.O. Expert Committee on Food Additives. Toxicological Evaluation of Some Food Colours, Emulsifiers, Stabilizers, Anti-cakin Agents and Certain Other Substances. W.H.O./Food Add./70.36. Geneva, World Health Organization, 1969.

2 U.S. Code of Federal Regulations Sec. 8.201. Federal Register 33 FR 8812 Washington, Government Printing Office, 1968.

The Colouring Matter in Food Regulations. S.I. 1203, 1966. London, H.M.S.O. 